\begin{tabular}{|c|c|c|c|c|c|c|}
\hline \multirow{4}{*}{ Impact Factor: } & ISRA (India) & $=3.117$ & SIS (USA) & $=0.912$ & ICV (Poland) & $=6.630$ \\
\hline & ISI (Dubai, UAE & $=0.829$ & РИНЦ (Russia) & $=0.156$ & PIF (India) & $=1.940$ \\
\hline & GIF (Australia) & $=0.564$ & ESJI (KZ) & $=8.716$ & IBI (India) & $=4.260$ \\
\hline & JIF & $=1.500$ & SJIF (Morocco) & $=5.667$ & OAJI (USA) & $=0.350$ \\
\hline
\end{tabular}

\section{SOI: 1.1/TAS DOI: 10.15863/TAS International Scientific Journal Theoretical \& Applied Science}

\author{
p-ISSN: 2308-4944 (print) e-ISSN: 2409-0085 (online) \\ Year: $2019 \quad$ Issue: $05 \quad$ Volume: 73
}

Published: $25.05 .2019 \quad$ http://T-Science.org
QR - Issue

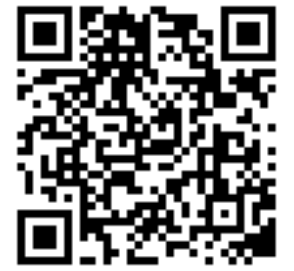

QR - Article

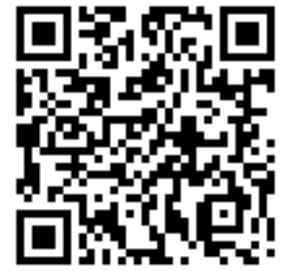

Abrar Saloxiddinovich Turaev Senior Lecturer of the Department of Social Sciences of the Jizzakh State Pedagogical Institute

\title{
NEOCONSERVATISM IN THE "GREATER MIDDLE EAST"
}

Abstract: This article analyzes the specifics of the neoconativative foreign policy of the United States in the Middle East Region, The Great Middle East concept of the neoconservators of the United States and the implementation of the neoconservative strategy implemented in the region.

Key words: neoconservatism, neoconservative foreign policy, USA foreign policy in the Middle East, The Great Middle East.

Language: Russian

Citation: Turaev, A. S. (2019). Neoconservatism in the "Greater Middle East". ISJ Theoretical \& Applied Science, 05 (73), 314-318.

Soi: http://s-o-i.org/1.1/TAS-05-73-44 Doi: crossef https://dx.doi.org/10.15863/TAS.2019.05.73.44

\section{НЕОКОНСЕРВАТИЗМ В "БОЛЫШОЙ БЛИЖНИЙ ВОСТОК"}

Аннотация: В статье анализируется специфика неоконсервативной внешней политики США $в$ Ближневосточном регионе, концепиия Великого Ближнего Востока неоконсерваторов США и реализачия неоконсервативной стратегии, реализуемой в регионе.

Ключевые слова: неоконсерватизм, неоконсервативная внешняя политика, внешняя политика США на Ближнем Востоке, Большой Ближний Восток.

\section{Введение}

События, произошедшие в настоящее время в регионе Ближнего Востока, по своей сути представляют собой глобальные особенности влияния. То есть в конце первой декады XXI века весь регион охватил процессы, называемые “арабской весной”. При этом сохраняется влияние мирового финансово-экономического кризиса и неэффективное завершение “иракской операции", что делает регион полигоном широкомасштабной борьбы. На современном этапе мирового развития, как правило, национальные, религиозные, региональные, глобальные, а также частные интересы становятся предметом международных отношений.

\section{Основная часть}

Ближний Восток занимает особое место на политической карте мира как регион богатый многовековой историей, наличием очагов напряженности, религиозным, национальным и культурным разнообразием. Постоянный рост интереса к региону также изменил взгляды на географические границы региона. С географической точки зрения территория, о которой мы говорим, признается как регион Ближнего и Среднего Востока. Даже в переводе с английского слово "Middle" означает "средний". Но в взглядах на политические теории и геополитическую роль регионов в основном используется слово, которое вместо английского "Near" означает “средний”. Поэтому в большинстве западных исследований термин Ближний Восток выражается словом, которое означает “средний " (Middle East). И в интерпретации происходящих в этом регионе процессов подчеркивают принадлежность к полному географическому пространству. Например, под названием страны Ближнего Востока стало традицией понимать территории ряда арабских государств, расположенных на севере Африканского континента, Ближнего Востока и всего Персидского залива, прилегающих к Каспийскому морю южных регионов, таких как Турция, Иран, Ирак, а также территорий Афганистана и Пакистана. В научных анализах и теориях отражается, что социальные процессы в этих регионах относятся к охвату 


\begin{tabular}{|c|c|c|c|c|c|c|}
\hline \multirow{4}{*}{ Impact Factor: } & ISRA (India) & $=3.117$ & SIS (USA) & $=0.912$ & ICV (Poland) & $=6.630$ \\
\hline & ISI (Dubai, UAI & $=0.829$ & РИНЦ (Russia & $=0.156$ & PIF (India) & $=1.940$ \\
\hline & GIF (Australia) & $=0.564$ & ESJI (KZ) & $=8.716$ & IBI (India) & $=4.260$ \\
\hline & JIF & $=1.500$ & SJIF (Morocce & $=5.667$ & OAJI (USA) & $=0.350$ \\
\hline
\end{tabular}

ближневосточного региона. Такой подход также встречается в неоконсервативных взглядах США. Во всех неоконсервативных внешнеполитических концепциях, связанных с регионом, интерпретируется не только географическое толкование Ближнего Востока, но и геополитическое измерение. В ходе широкомасштабной неоконсервативной практики, начавшейся с приходом Республиканской партии в правительство США (2000 год), внимание к региону также было усилено. Были выдвинуты новые идеи о геополитических масштабах региона и зоне интересов США. В частности, можно сказать о возникновении таких терминов, как “Великий Ближний Восток“, "Большой Ближний Восток” и "Новый Ближний Восток". Стремление к отклонению от первоначальной географической сущности региона, безусловно, обусловлено такими факторами, как идеология глобализации и гегемонизма. Скорее всего, быстро переместится в другое место в случае, если событие, которое происходит сегодня в одном месте земного шара. А для гегемонизма расширение границ регионов служит отличным инструментом для усиления масштабов воздействия. Таким образом, неоконсервативная внешняя политика США в регионе отличается своей широкой эффективностью и всесторонней заинтересованностью. Внешнеполитические концепции, сформулированные именно по отношению к региону Ближнего Востока, также могут серьезно повлиять на безопасность соседних регионов с точки зрения их охвата. В частности, в период после событий 9/11 в межрегиональных отношениях опасения по поводу такой ситуации значительно усиливаются. Например, “демократические революции”, которые произошли в регионах Восточной Европы и Центральной Азии, также вызвали некоторую стагнацию межрегиональных активных отношений.

В последние годы лозунги или другие идеи по преодолению современных проблем Ближнего Востока, в частности, под флагом демократизации, стали продвигаться рядом новых концепций, стратегий представителями политических кругов США и неоконсерваторами. "Человечество стало свидетелем того, что политико-военные группы страны очень мастерски использовали “американское преимущество”, “завещание предков”, “американскую ответственность” и другие мифы, сформулированные на уровне массового сознания в течение многих лет. В частности, одна из основных причин, по которой компания не принесла ожидаемых результатов в 1997-2001 годах, связана с тем, что мир глубоко осознал ее глубинную сущность”, - отмечает Т.Джураев.
После военных действий США в Афганистане и Ираке республиканским правительством были предприняты усилия по созданию и внедрению в практику концепций, на которых были созданы теоретические основы в течение 1990-х годов при активном участии неоконсерваторов. Под влиянием американских неоконсерваторов была сформирована и представлена широкой общественности система неоконсервативных взглядов, объясняющая широкий смысл региона Ближнего Востока. Одним из таких взглядов является концепция “Большого Ближнего Востока", которая была разработана в 2003 году и до сих пор признается как "Новый Ближний Восток" с рядом обновлений. Согласно заявлению представителя администрации США, в географическую широту “Большой Ближний Восток” входят следующие страны: Северная Африка (Марокко, Алжир, Тунис и Ливия), традиционный Ближний и Ближний Восток и Персидский залив (Египет, Израиль, Сирия, Иордания, Ливан, Йемен, Ирак, Саудовская Аравия, ОАЭ, Кувейт, Бахрейн, Оман, Катар), а также Иран, Афганистан и Пакистан. По мнению ряда американских специалистов, Турция также относится к этому региону. Они также добавляют Кавказ и Центральную Азию из бывших советских республик. По мнению Вашингтона, главной особенностью объединения на Большой Ближний Восток является то, что многие из них имеют те или иные источники международного терроризма, распространение оружия массового уничтожения, политическую и экономическую нестабильность.

По мнению ряда экспертов, основной целью этих стратегий является укрепление позиций Израиля и формирование структур, поддерживающих интересы США. Иранские эксперты считают, что "Большой Ближний Восток” - это зависимость региона от США, ослабление "политического ислама", недопущение “исламского возрождения”, свержение неприемлемых структур. По их мнению, в рамках реализации концепции “Большой Ближний Восток” в целом задачи США заключаются в следующем: повышении роли и защите интересов Израиля на Ближнем Востоке; создании возможностей для США в нефтедобыче; давлении на Иран; задачах в области культурной и идеологической политики.

Одним из новых концепций, которые вызывают обсуждение многих экспертов, является проект “Новый Ближний Восток” (New Middle East). Эта концепция сформулирована в полном неоконсервативном духе, демонстрируя важные аспекты внешней политики США после 2000-х годов. Предложение "Новый Ближний Восток" впервые появилось в июне 2006 года госсекретарем США.Райс был объявлен в своем 


\begin{tabular}{|c|c|c|c|c|c|c|}
\hline \multirow{4}{*}{ Impact Factor: } & ISRA (India) & $=3.117$ & SIS (USA) & $=0.912$ & ICV (Poland) & $=6.630$ \\
\hline & ISI (Dubai, UAI & $=0.829$ & РИНЦ (Russia & $=0.156$ & PIF (India) & $=1.940$ \\
\hline & GIF (Australia) & $=0.564$ & ESJI (KZ) & $=8.716$ & IBI (India) & $=4.260$ \\
\hline & JIF & $=1.500$ & SJIF (Morocco & $=5.667$ & OAJI (USA) & $=0.350$ \\
\hline
\end{tabular}

выступлении в Тель - Авиве в качестве места для "Greater Middle East" (Великий Ближний Восток). Одним из его существенных аспектов является то, что он признан одновременно с запуском нефтяного терминала Баку - Тбилиси - Джейхун. К постановлению правительства, как сообщает К.Райс, проект "Новый Ближний Восток" начинается с Ливана. По мнению экспертов, этот призыв является подтверждением “дорожной карты " англо - американско -Израиля на Ближнем Востоке. Он будет направлен на создание по региону сил “творческого хаоса", создающего условия для возникновения очагов войны и хаоса.

Профессор М.Левин сказал, что неолиберальные глобалисты и неоконсерваторы, а также правительство Дж.Буша реализует стратегию “творческого уничтожения" на пути создания своего нового мирового порядка.

С развитием "Нового Ближнего Востока" появилась и его карта. Карта "Новый Ближний Восток" Считается важной частью книги отставной военный Р.Питера "Никогда не прекращай борьбу “(Never Quit The Fight), которую он представил публике 10 июля 2006 года. Кроме того, это карта также напечатаны Р.Петерсом в журнале вооруженных сил США под заголовком "Кровавые границы: Как выглядеть на Ближнем Востоке".( Blood Borders: How a better Middle East woold look) Р.Петерс признал, что ограничения в Ближневосточном регионе на сегодняшний день не соответствуют исторической, этнической, национальной действительности. Поэтому проблемы не решаются. Это предполагает изменение границ. Изменения могут произойти в результате возникновения напряженной политики между государствами, вооруженных конфликтов, вызванных внутренними и межконфессиональными конфликтами в государствах.

Территория, которая претерпела множество изменений на карте "Новый Ближний Восток", может стать территорией Ирака. Он делится на три анклава: суннитский, шиитский, курдский. В то же время по этой концепции в регионе появляются новые государства: курдское государство, арабское шиитское государство, свято-исламское государство, Белуджистанское государство. Анализ карты "Новый Ближний Восток" показывает, что происходящие изменения усложняют политико-военную ситуацию в регионе. Взаимозаменяемость или отчуждение государств со своей территории может привести к неразрешимому конфликту. Несомненно, влияние неоконсервативных теоретиков на формирование таких инициатив было высоким. В частности, У.Кристол, как и во время учебы в университете, высказывал такое мнение: “..Миссия начинается в
Багдаде, но не заканчивается там. Мы находимся в начале новой исторической эры. И он не ограничивается Ираком. И даже на следующем Ближнем Востоке не ограничится. Этот период связан с ролью США в XXI веке".

Внедрение неоконсервативных идей, сформулированных в последние десятилетия XX века, и их применение во внешнеполитических стратегиях не только оказывают свое влияние на современные процессы на Ближнем Востоке. Такие понятия, как “Большой Ближний Восток”, “Большой Ближний Восток” и “Новый Ближний Восток”, которые логически дублируют и дополняют друг друга, направлены на обеспечение геополитических и геоэкономических интересов США под идеями решения проблем современного Ближнего Востока, такие инициативы, как "Большая Центральная Азия”, “Большой Ближний Восток”, “демократическое избирательное сообщество”, выдвигаемые определенными западными политическими кругами, являются выражением политических, экономических и других интересов силовых центров.

Возможно, продвижение таких идей и создание современных геополитических карт “...сегодняшний мир должен способствовать реализации национальных интересов США. Реализация стратегии национальных интересов США на определенном уровне основывается не только на ее безупречной разработке, но и на приоритетах, которые, напротив, связаны с огромными военными стратегическими, экономическими возможностями".

Для обеспечения своих интересов на Ближнем Востоке иногда считается важным создание новых проблем, политика ускорения их существования. Также сложилась ситуация глобализации интересов для осуществления и защиты национальных интересов. По мнению экспертов, глобализация национальных интересов является первым и основным недостатком глобализации. Потому что это поведение может привести к политической гегемонии.

Современные геополитические процессы и их негативные последствия позволяют неоконсерваторов серьезно наблюдать. Потому что резкая политика или разработанные стратегии, которые были сделаны для выполнения национальных интересов, не всегда дают ожидаемые результаты. Например, свержение Ирака является одним из резких оттоков, которые произошли в регионе в последние десятилетия. В политическом плане в стране образовался парадокс. Убийство Саддама Хусейна и его прямая трансляция в массы привели к радикализации сторонников Саддама Хусейна среди населения. В стране началась беспрецедентная конкуренция и битва между 


\begin{tabular}{|c|c|c|c|c|c|c|}
\hline \multirow{4}{*}{ Impact Factor: } & ISRA (India) & $=3.117$ & SIS (USA) & $=0.912$ & ICV (Poland) & $=6.630$ \\
\hline & ISI (Dubai, UAI & $=0.829$ & РИНЦ (Russia & $=0.156$ & PIF (India) & $=1.940$ \\
\hline & GIF (Australia) & $=0.564$ & ESJI (KZ) & $=8.716$ & IBI (India) & $=4.260$ \\
\hline & JIF & $=1.500$ & SJIF (Morocce & $=5.667$ & OAJI (USA) & $=0.350$ \\
\hline
\end{tabular}

шиитами, курдами и суннитами. Страна была практически разрушена с экономической точки зрения. В результате войн на многие нефтеперерабатывающие заводы поступает трава. Нефтяная отрасль страны идет по стопам всей ее целостности. Кроме того, в целом беспорядки на Ближнем Востоке продолжают усиливаться. Это не исключает возможности того, что конфликты будут иметь международный характер в сочетании друг с другом.

Протесты, начавшиеся в январе 2011 года с целью возобновления внутренней жизни стран Северной Африки и Ближнего Востока, превратились в геополитическое противостояние, которое началось в марте. Вот уже несколько лет беспорядки, охватывающие всю Сирию, сегодня стали буквально войной. Если подходить к вопросу с геополитической точки зрения, то станет известно, что Сирия и Иран остались в списке стран, находящихся на политической позиции, противоречащей интересам США на Ближнем Востоке.

Согласно анализу, Сирия является самой важной частью планируемой Арабской газопровода. Центральная роль Сирии в арабской газопроводной сети играет ключевую роль в понимании того, что именно Сирия празднуется. Конечно, помимо этих факторов, существующая в Сирии внутриполитическая ситуация, внутренние разногласия, борьба за власть, религиозноэтнические конфликты приводят к тому, что Сирия становится очагом гражданской войны. В целом, продолжающийся в Сирии политиковоенный кризис в виде гражданской войны оказывает негативное влияние на обеспечение региональной и глобальной безопасности. В частности, это может серьезно повлиять на политику стабильности, межнациональной и религиозной толерантности в Центральной Азии. В частности, волнообразие “цветных революций” через различные социальные сети может привести к политической нестабильности в результате замедления реформ модернизации и обновления, происходящих в государствах региона, искусственного ускорения законов формирования гражданского общества. Следует помнить, что в 2002 году бывший президент США Дж. Буш включил Сирию в систему “ось зла” и включил ее в число государств, которые были намечены после изменения структуры в Ираке. Хотя, несмотря на преобладание демократических позиций в государственном управлении США, наблюдается практика изменения сирийского режима. На этом месте стоит обратиться к новой карте Ближнего Востока. Потому что на этой карте отражены границы нового "мусульманского государства". Эту ситуацию можно объяснить деятельностью
ИГИЛ который является ярким примером нынешней лиги джихадистов. То есть в определенном смысле неоконсервативные теории переходят на практику. Это означает, что для понимания сущности геополитических процессов, происходящих сегодня на Ближнем Востоке, требуется анализ последовательности процессов, происходящих вокруг иракской и сирийской геополитической линии Большого Ближнего Востока.

\section{Вывод}

В целом, резкое противостояние, вооруженные столкновения, происходящие в регионе в последние годы, делают регион огромным полигоном глобального терроризма.

Широкомасштабные

процессы "демократизации“, начатые волной революционных процессов “арабской весны", поставили под угрозу разгром крупного военнополитического кризиса. Следует отметить, что проекты неоконсервативной демократизации, сформированные в начале 90-х годов, попрежнему ведут борьбу за все еще существующую практику. Однако становится очевидным, что применение "мягкой силы " не всегда дает свой ожидаемый результат. Поэтому в американском сообществе также резко возросла критика неоконсервативных взглядов.

Таким образом, можно сделать следующие выводы о роли и влиянии неоконсервативных идей США в геополитических процессах в новом ближневосточном регионе:

Во-первых, в результате инициатив, начатых с борьбы с международным терроризмом, гармонизированных с идеями демократизации и искоренения авторитарных структур, в социальнополитической лексике появилось понятие "Новый Ближний Восток;

Во-вторых, обновленный и обогащенный Ближний Восток был представлен как эффективный механизм реализации неоконсервативных идей;

В-третьих, несмотря на снижение чувствительности к воздействию неоконерваторов в государственном управлении США, интервенционный интервенционный интервенционный мониторинг США между военными или некоммерческими средствами активно продолжается;

В-четвертых, исполнение интересов американских неоконструкторов продолжает негативно влиять на позиции США в международной арене, и необходимость нового правительства демократов в проведении активной политики интернационализма была актуальной. 


\begin{tabular}{|c|c|c|c|c|c|c|}
\hline \multirow{4}{*}{ Impact Factor: } & ISRA (India) & $=3.117$ & SIS (USA) & $=0.912$ & ICV (Poland) & $=6.630$ \\
\hline & ISI (Dubai, UAE & $=0.829$ & РИНЦ (Russia & $=0.156$ & PIF (India) & $=1.940$ \\
\hline & GIF (Australia) & $=0.564$ & ESJI (KZ) & $=8.716$ & IBI (India) & $=4.260$ \\
\hline & JIF & $=1.500$ & SJIF (Morocce & $=5.667$ & OAJI (USA) & $=0.350$ \\
\hline
\end{tabular}

\section{References:}

1. Jo'raev, S. (2007). Zamonaviy xalqaro munosabatlar. (p.5). Tashkent: Akademiya.

2. Jo'raev, T. (2007). Milliy davlatchilik: xavsizlik va barqarorlik (Global kontekst). (p.101). Tashkent: Akademiya.

3. Mirskiy, G. I. (2007). Bolshoy Blijniy Vostoksamiy konfliktniy region mira. Retrieved 2019, from

http://www.wpec.ru/text/200704171449.htm

4. Nazemroaya, M. D. (2006, November 18). Plans for Redrawing the Middle East: The Project for a "New Middle East" Retrieved 2019, from http://www.globalresearch.ca/index.php?contex $\mathrm{t}=$ viewArticle $\&$ code $=$ NAZ20061116\&articleId $=3882$

5. Levine, M. (2006, August 22). The New Creative Destruction // Asia Times. Retrieved 2019, from
http://www.atimes.com/atimes/Middle_East/H H22Ak01.html

6. Brzezinski, Z. (1997). The Grand Chessboard: American Primacy and Its Geo-strategic Imperatives. New York City: Basic Books. Retrieved 2019, from http://www.perseusbooksgroup.com/basic/book detail.jsp?isbn=0465027261.

7. Gracheva, T. V. (2004, Dec.16). Voennaya politika SSHA skvoz prizmu filosofii i personaliy Retrieved 2019, from http://www.bestreferat.ru/referat-2126.html

8. Jo'raev, T., \& Akobirov, S. (2007). Milliy manfaatlar va milliy xavfsizlik. (p.118). Tashkent: Akademi.

9. Jo'raev, S., Saodolimov, S., \& Abdug'anieva, Z. Xalqaro xavfsizlik. (p.51). Tashkent: Akademiya. 